\title{
Andragogia: um olhar para o aluno adulto
}

\section{Resumo}

O presente artigo pretende destacar a importância de um ensino direcionado ao aluno adulto, não só pelo fato de adultos e crianças aprenderem de formas diferentes, mas principalmente pelas mudanças ocorridas nos últimos dois séculos e que revolucionaram a forma de o indivíduo interagir com o entorno. Essas mudanças são de ordem histórica, social e tecnológica e representam a construção de um sujeito cuja condição humana sofreu profundas modificações. Ao referirmo-nos a alunos adultos, podemos destacar diferentes públicos, todavia, nosso olhar estará voltado aos alunos do Ensino Superior, que cursam instituições particulares.

\section{Abstract}

This article aims to highlight the importance of an education directed to the adult learner, not only because adults and children learn in different ways, but mainly by changes in the last two centuries that have revolutionized the way individuals interact with the environment. These changes are historical, social and technological developments and represent the construction of a human subject whose condition has undergone profound changes. When referring to adult learners, we can highlight different audiences; however, our attention will focus on students in Higher Education, who attend private institutions.
Palavras-chave: andragogia, educação, ensino superior, aprendizagem.

Keywords: andragogy, education, higher education, learning.

\section{Apresentação}

Apesar da urgência de um ensino destinado ao público adulto, ainda há poucos estudos a respeito de Andragogia. Pretendemos discutir o assunto e apontar a urgência de pesquisas nesse segmento, especialmente pelo enfoque que é dado ao conhecimento em nossa sociedade. É fundamental esclarecer que nosso objetivo não é o de insinuar uma divisão entre Pedagogia e Andragogia, mas apontar que Andragogia faz parte dessa ciência, que é a Pedagogia, ou seja, a questão primordial é estabelecer distinção entre as formas de aprender centradas na criança e no adulto e a necessidade desse entendimento para didáticas mais efetivas. A Andragogia representa outro aspecto dos princípios da aprendizagem.

Para isso, traçaremos um breve histórico acerca da questão como subsídio para entendimento de alguns aspectos dessa ciência, principalmente pelo fato de a condição humana ter mudado significativamente, o que fez com que os indivíduos alterassem a forma de participar do processo de construção social, histórica e tecnológica. Essa tríade requer o estabelecimento de novas reflexões frente à

\footnotetext{
${ }^{1}$ Cimara Apostólico - Mestre em Comunicação e Semiótica - PUC-SP. Corretora de dissertações e teses. Professora da Fac. Guaianás. Profa. Pesquisadora da FICS onde desde o primeiro semestre de 2012 compõe a Grupo de Pesquisa Oficina de Artigos è orientadora de Iniciação Científica é menbro da Comissão de Edição, Revisão, diagramação e Editoração Eletrônica Augusto Guzzo das Faculdades Integradas Campos Salles - FICS. www.campossalles.edu.br
} 
maneira como entendemos a aprendizagem e mais que isso, como nós - docentes - lidamos com os diferentes públicos $\mathrm{e}$ as várias expectativas.

Apoiaremos nossas ideias em alguns pensadores para maior compreensão desse novo sujeito agente, tentando vislumbrar os caminhos pelos quais devemos nos imbricar para alcançar e atingir este público. Neste trabalho, direcionaremos nosso olhar para o aluno do Ensino Superior dos cursos Tecnológicos e Graduação, partilhando nossa preocupação com relação à Didática empregada para esse ensino.

\section{Breve Histórico sobre Andragogia}

Há concepções acerca de técnicas e desenvolvimento de aprendizagem docente, todavia, existem poucos estudos voltados especificamente aos alunos adultos. Também falta um olhar que contemple os aspectos afetivos, motivacionais que possam favorecer maior envolvimento entre professor e aluno.

Ao pensarmos em Educação, sabemos que o desenvolvimento da sociedade está associado à escolarização da população; isso significa que é imprescindível investirmos nesse segmento para formação dos indivíduos, propiciando condições para tomada de decisões mais conscientes e assertivas nos diversos âmbitos da vida.

As pesquisas na área de Educação demonstram preocupação e busca de estratégias no sentido de aperfeiçoar a maneira como os conteúdos são construídos. Consideramos importante refletir até que ponto essa transposição de conhecimentos promoverá mudanças na maneira de agir e interagir com os demais indivíduos. Não é possível descartar o conhecimento como ponte para um saber emancipatório, entretanto, sabemos que essa construção demanda atitudes, que precisam ser desenvolvidas.
Também não apreciamos a ideia de restringir determinados ensinamentos à primeira infância ou a educação recebida pelos pais, isso não significa que pretendemos descartar a importância dessa base inicial, mas nossa preocupação é de expandir a discussão para a possibilidade de ensinarmos mais do que conteúdo aos nossos alunos de Ensino Superior.

Considerando o contexto atual - mudanças nas demandas socioeconômicas e mercadológicas, não é de se estranhar a quantidade de cursos tecnológicos que surgem, na última década, para suprir a velocidade do mercado decorrentes das novas tecnologias e da deficiência de formação presente no Ensino Médio, que não prepara o indivíduo para atuar como especialista. Dessa maneira, podemos compreender o aumento do ingresso de alunos na Educação Superior e, portanto, a importância de falarmos sobre Andragogia.

Retomando ao ponto inicial de nossa discussão, entendemos que o conceito de Pedagogia costuma ser relacionado primeiramente com aprendizagem de crianças, mas sabemos que essa área também abrange o público adulto. Todavia, constatase que a valorização dada ao ensino de adultos tem recebido tratamento secundário. Vogt e Alves no Artigo Revisão Teórica sobre a Educação de Jovens e Adultos para uma aproximação com a pedagogia traçam um breve histórico sobre o assunto:

O termo andragogia foi formulado originalmente por Alexander Kapp, professor alemão, em 1833; caiu em desuso e reapareceu em 1921, no relatório de Rosenstok, sinalizando que a educação de adulto requer professores, métodos e filosofia diferenciados. Eduard Lindeman, em 1927, adotou o termo de Rosenstock e usou-o poucas vezes nos Estados Unidos. O vocábulo andragogia foi utilizado amplamente, desde a década de 60, na França, Yugoslávia e Holanda para se referir à disciplina que estuda o processo da instrução de adulto ou a ciência da educação de adulto. (VOGT e ALVES, 2005). 
Malcolm Knowles tornou-se referência no assunto, após estudar distinções entre Pedagogia e Andragogia, que é, de maneira simplificada, o ensino para adultos; aprendizes autônomos e professores como facilitadores na aprendizagem.

Internacionalmente, a preocupação também não é tão recente; em 1949 a UNESCO realiza a primeira conferência concernente à questão:

Desde a primeira conferência sobre Educação de Adultos em 1949, a UNESCO tem trabalhado com os Estados-membros para assegurar que os adultos exerçam o direito fundamental à Educação. Em 1976, a Conferência Geral da UNESCO aprovou a Recomendação de Nairóbi para o desenvolvimento da educação de adultos, que consagrou o compromisso dos governos em promover a educação dos adultos como parte integrante do sistema educacional, numa perspectiva de aprendizagem ao longo da vida. (UNESCO, 2010, pág.12)

Em Dezembro de 2009 foi realizada a última, a sexta conferência sobre a questão, CONFINTEA (Conferência Internacional de Educação de Adultos) com o tema Elos Perdidos das Metas das décadas do milênio. A discussão priorizou a importância de redobrar os esforços para reduzir o índice de analfabetismo. $\mathrm{O}$ primeiro compromisso estabelecido foi desenvolver "uma oferta de alfabetização que conduza à obtenção de conhecimentos, capacidades e competências funcionais e sustentáveis pelos participantes, empoderando-os para que continuem a aprender ao longo da vida" (UNESCO, 2011, pág. 4).

Sabe-se que Educação e Sociedade são conceitos intrinsecamente ligados, ou seja, considerando que as nações buscam manter o status de civilização, torna-se prioritária a alfabetização para que as pessoas tenham condições de inserir-se socialmente, em busca do saber emancipatório.

\section{Em busca do saber emancipatório}

A Andragogia é a ciência que se preocupa com o aprendizado do adulto, buscando pensar estratégias que o auxiliem a alcançar esse saber emancipatório de que se tem tratado com mais ênfase nos últimos anos. Neste sentido, a Didática precisa ser diferenciada e contemplar os aspectos do indivíduo maduro. Knowles aponta cinco premissas, que mudaram a perspectiva de ensino voltado às crianças para o foco em adultos.

$\mathrm{O}$ autoconceito, que é o primeiro elemento, aponta a distinção entre dependente e autodirigido. A criança estabelece uma relação de dependência com o professor, já o adulto ele precisa ser direcionado, orientado, mas é ele quem deve fazer escolhas.

O segundo item relaciona-se a experiências $-o$ adulto obviamente tem muito mais experiência que a criança. Nesse sentido, ele será capaz de interpretar, transformar e dar sentido às várias situações de aprendizagem.

O terceiro ponto é a prontidão a aprender centrada nos papéis sociais - a criança habita seu mundo particular e ainda não consegue se situar numa perspectiva de espaço e tempo social.

O próximo é a perspectiva de tempo - os adultos aprendem à medida que conseguem vislumbrar aplicação prática e breve às situações-problemas. O último é a motivação, que no indivíduo amadurecido precisa ser trabalhada com outros propósitos, em função dos quatro primeiros itens apontados nessa breve descrição. Knowles apontado na tabela 1 sumarização dessas distinções: 


\begin{tabular}{|l|l|}
\hline Autoconceito & Ser de personalidade dependente para um autodirigido. \\
\hline Reservatório de experiência & $\begin{array}{l}\text { Acumula e se transforma em um recurso crescente para } \\
\text { aprender. }\end{array}$ \\
\hline Prontidão a aprender & $\begin{array}{l}\text { Torna-se orientada, cada vez mais, às tarefas de } \\
\text { desenvolvimento de seus papéis sociais. }\end{array}$ \\
\hline Perspectiva de tempo & $\begin{array}{l}\text { Muda de uma procrastinação do conhecimento à imediata } \\
\text { aplicação e orientação, sendo que a orientação da } \\
\text { aprendizagem desloca-se de uma aprendizagem centrada } \\
\text { nas disciplinas a uma centrada no problema. }\end{array}$ \\
\hline Motivação & É interna no indivíduo amadurecido. \\
\hline
\end{tabular}

Tabela 1 - Diferenciação entre crianças e adultos

Fonte: Knowles, 1980, pág. 44-45

Compreendemos que o ser adulto está preocupado com a aplicação imediata do conteúdo aprendido; conforme dito, o ensino deve estar centrado em situações-problema, tendo que em vista que ele precisa vislumbrar resultados em curto prazo, principalmente no que tange à capacitação profissional e que possam ajudá-lo na manutenção das necessidades primárias e secundárias, conceito mencionado por Maslow ${ }^{2}$. $\mathrm{O}$ ensino passa a ser uma moeda de troca "mercari" ele precisa ver finalidade, utilidade e retorno, caso contrário prefere investir o tempo em outras atividades. Gadotti realizou uma pesquisa densa em relação ao aluno adulto que ainda não é alfabetizado, corroborando ao explicar:

O aluno adulto não pode ser tratado como uma criança cuja história de vida apenas começa. Ele quer ver a aplicação imediata do que está aprendendo. Ao mesmo tempo, apresenta-se temeroso, sente-se ameaçado, precisa ser estimulado, criar autoestima, pois sua "ignorância" lhe traz tensão, angústia, complexo de inferioridade. Muitas vezes tem vergonha de falar de si, de sua moradia, de sua experiência frustrada da infância, principalmente, em relação à escola. É preciso que tudo isso seja verbalizado e analisado (GADOTTI. 2003 pág.39).

O autor acrescenta: "A Andragogia tem ensinado que a realidade do aluno adulto é diferente da realidade da criança, mas ainda não incorporamos esse princípio em nossas metodologias. (GADOTTI, 2003, pág. 39)”.

Por meio de nossas experiências, é possível constatar que esse discurso também é aplicável ao aluno do ensino superior cuja história de vida acompanha e interfere na forma como ele recebe e interpreta o que lhe é transmitido, além, é claro da pressão e cobrança social para que desempenhe cada vez melhor suas tarefas.

Nessa sociedade da informação, conforme descreve Maria da Glória Gohn a dominação e controle são referências. A autora amplia a discussão por meio das métaforas das ondas de Alvin Tofler; "a terceira onda se baseia na substituição da força muscular pela força mental como fator de produção. Ela ultrapassa os limites da economia e da tecnologia, provocando mudanças sociais profundas, bem como mudanças culturais, morais e institucionais" (GOHN, 2008, pág. 66).

Essas mudanças implicaram em valores diferentes; o que antes estava centrado na força bruta do homem e na valorização de bens materiais como riqueza deixa de ser relevante dando lugar ao conhecimento. As competências passam por uma severa revisão, assim, a necessidade de desenvolver

\footnotetext{
${ }^{2}$ Segundo Abraham Maslow as necessidades dos seres humanos estão colocadas em categorias. São elas: primárias necessidades fisiológicas e de segurança. Secundárias - necessidades sociais, de estima e de autorrealização.
} 
operações mentais cada vez mais complexas com vistas a delinear uma visão sistêmica, imaginação e criatividade, consciência dos aspectos éticos, inteligência ecológica e, principalmente, o saber-fazer "savoirfaire" (articular) são condições essenciais para aquisição da nova riqueza ou capital cultural $^{3}$, conforme denominado por Pierre Bourdieu.

O termo "articular" foi selecionado propositadamente, uma vez que 'o saber precisa culminar em competências', pois de nada adianta uma sociedade repleta de indivíduos obesos de cognição, imaginação etc., que não conseguem colocá-los em prática. E, sobretudo, fazê-lo de maneira eficiente e eficaz.

Nessa breve passagem, podemos inferir a importância de formar um indivíduo competente do ponto de vista cognitivo, não perdendo de vista que o saber emancipatório é processual e depende dos valores e caminho trilhados para a formação desse homem integral, - formar e agir são palavras-chave que devem permear o ensino superior, que independe de faixa etária, conforme veremos a seguir.

\section{Plasticidade cerebral}

Mas, o ágon entre homem e conhecimento não é tão simples de desenlear; o homem é um ser sócio-histórico permeado por construções e desconstruções frequentes. $\mathrm{O}$ estudante adulto não é uma folha em branco ${ }^{4}$, ele já vem com uma bagagem, que se por um lado é base para dar significado ao aprendizado, por outro, torna-se limitante, pois crenças, condicionamentos impedem a revisão de ações enraizadas, restringindo seu crescimento.

Reiterando o que já foi dito, as exigências atuais requerem a revisão de alguns conceitos, conforme podemos compreender com Makeliny Oliveira (2009: pág.65 e 66).

O primeiro é o da inteligência, que durante décadas se acreditou ser imutável e mensurável, ou seja, o ser já nascia com um nível de inteligência determinado. De maneira reducionista, é o entendimento da inteligência como dom.

O segundo conceito é o de criatividade, que era considerada como ferramenta de alguns privilegiados. O terceiro é o de memória, que era tida como um receptáculo cujo objetivo era acumular informações.

Vejamos, sem a consideração de que o homem também aprende socialmente, conforme o meio em que está inserido, não é possível sobrepujar esses equívocos. O conceito de plasticidade cerebral precisa ser considerado, pois o homem tem condições de aprender, independentemente de sua idade. Esse conceito inclui também o aspecto biológico:

Atualmente com o avanço dos estudos dos
neurocientistas, descobriu-se que o conceito de
inteligência como algo imutável não condiz
com a realidade humana. Dessa forma, esse
conceito foi reformulado, pois se acredita que é
na vivência que o homem vai se constituindo e
se transformando, podendo mudar não só o
meio sociocultural em que vive, mas também o
biológico (plasticidade cerebral). Assim, a
inteligência é compreendida atualmente como
um processo dinâmico, construído na interação
do sujeito com a cultura, e pode ser
desenvolvida independentemente da idade da
pessoa. (NOGUEIRA, 2009, pág. 65).

\footnotetext{
3 Por recursos ou poderes, Bourdieu entende mais especificamente o capital econômico (renda, salários, imóveis), o capital cultural (saberes e conhecimentos reconhecidos por diplomas e títulos), o capital social (relações sociais que podem ser revertidas em capital, relações que podem ser capitalizadas) e por fim, mas não por ordem de importância, o capital simbólico (o que vulgarmente chamamos prestígio e/ou honra). SETTON, Maria da Graça Jacinto. Disponível em: $<$ http://renatadbc.web.officelive.com/Pierrebourdieu.aspx>. Acesso em: 24 set.2011

${ }^{4}$ Comenius em seu livro Didactica Magna comenta sobre a importância de iniciar a Educação desde cedo, quando, segundo ele a mente ainda não foi ocupada, principalmente por preconceitos e valores mundanos (COMENIUS, 1621-1657, pág. 35).
} 
Quando partimos do pressuposto inatista, torna-se compreensível limitar o conceito de ensinar à mera transposição de conteúdos ao aluno. Naturalmente considerando que o aluno já tem condições de aprender e principalmente, que nessa concepção, o aluno é o responsável pelo próprio aprendizado. Não vamos entrar na discussão de responsabilidades, mas apenas aproveitar a ideia para poder aprofundar um pouco mais a questão. Vejamos, se o aluno é responsável pelo próprio aprendizado - ao professor cabe o papel informativo. Nesse sentido, o aluno que quiser, tiver interesse e principalmente condições cognitivas para acompanhar obterá sucesso; os demais, portanto, serão excluídos do processo, pois nasceram sem o "dom", sem condições para entendimentos mais complexos.

Apesar da obviedade, muitos de nós temos agido dessa maneira com nossos alunos, funcionários e inclusive pessoas próximas a nós.

Consideramos que o outro não consegue entender o que estamos tentando transmitir. É raro alguém assumir que não sabe se comunicar adequadamente, que entende as informações de maneira distorcida ou que é necessário verificar com mais profundidade o assunto. O que é muito comum ouvir é "Não falou coisa com coisa", "não disse nada com nada" etc.

Alguns generalizam afirmando que o ser humano é assim mesmo, como se todas as nossas experiências fossem similares e passassem pelos mesmos processos de desenvolvimento durante a vida. Nesse sentido, devemos indagar como ficam as nossas representações. A nossa capacidade simbólica não interfere na percepção que temos dos objetos? Devemos considerar, portanto, que tudo tem a mesma representação o tempo todo para os diversos indivíduos?

\section{Professor-Gestor}

Dentre as necessidades de nossa sociedade, citamos a busca por constante atualização profissional e uma das formas de fazê-lo é cursando o ensino superior: tecnológico ou graduação.

$\mathrm{O}$ aluno que ingressa em um desses cursos, não necessariamente atua na área escolhida, por isso, a figura do professor é representativa para aproximar os conceitos teóricos e práticos.

O professor é um especialista na sua área de atuação e possui pleno domínio dos conteúdos, todavia, não é mais possível considerar que o conhecimento, a bagagem do mestre é suficiente para o entendimento do aluno.

Muito se tem estudado sobre a Didática, derivada do grego didaktiké, que tem o significado de arte de ensinar e também está relacionada ao termo techné - prática e como ela pode favorecer as práticas em sala de aula. No entanto, o estudo das técnicas só será válido a partir do momento em que houver uma reflexão por parte do grupo docente sobre sua aplicação em suas práticas. Infelizmente, essa questão nem sempre é bem vista, pois alguns têm dificuldades em lidar com autoavaliações e principalmente, rever paradigmas.

Apesar de o aluno adulto aprender diferente da criança, é preciso esclarecer que ele precisa do professor que intermedeia o entendimento dos diferentes conteúdos. O professor é referência nos processos de ensino-aprendizagem, pois seu papel é de propiciar significado àquilo que está sendo transmitido, caso contrário é preferível que o aluno estude a distância e assuma para si todas as representações possíveis do processo, deslocando-se até a faculdade apenas para realização das avaliações. Assim, a didática é fundamental para facilitar a compreensão do que se pretende alcançar. Não se trata, portanto, apenas de conhecer o conteúdo, mas 
de elaborar estratégias que auxiliem os discentes.

As estratégias de ensino-aprendizagem precisam ser conduzidas consciente e eficazmente. Ainda há muitas dificuldades neste sentido, pois a utilização, por exemplo, de dinâmicas em sala de aula pode caracterizar "passatempo". Além disso, há uma tendência a limitar dinâmica ao aspecto motivacional. Não descartemos essa possibilidade, mas é preciso abarcar todas as possibilidades que a ferramenta oferece. Também é necessário verbalizar os objetivos a serem alcançados; as aplicações que podem ser estabelecidas em outros âmbitos, inclusive, colaborando com o aluno na associação da atividade com o conceito que se pretende demonstrar e assim por diante.

O planejamento sistêmico da aprendizagem é o ponto-chave para evitar improvisações dispersivas, sem ordem. Para que esse seja bem realizado, são necessários critérios que incluem revisão do programa utilizado, bibliografias atualizadas, fixação dos objetivos, avaliação diagnóstica para saber o estágio do aluno, evitando desta forma apriorismos. Devem ser consideradas as demandas sociais para que o aluno não aprenda de maneira dissociada do uso prático, portanto, os problemas reais ou ainda a representação desses problemas compõem o aprendizado.

Hoje contamos com tecnologias, que alteraram a maneira de apreensão dos saberes - os sistemas estão complexos e dinâmicos, havendo diversas opções mais atraentes que a aula expositiva do professor, esse é um agravante que exige uma revisão urgente. A questão a ser respondida é diante de tantos elementos interativos e mais atraentes, como compartilharemos esses saberes com os alunos adultos?

Ao estabelecermos uma analogia com produtos, podemos afirmar que o conhecimento tem uma vida útil relativamente curta, requer atualizações frequentes e velozes. Os indivíduos lidam com a dificuldade em administrar o próprio tempo, que parece cada vez mais limitado. Nesse universo de informações sentimo-nos dispersos e com dificuldades em ser mais assertivos. Aliado a esses elementos, a maioria dos indivíduos, ao longo da história, sempre teve dificuldades em rever os paradigmas - há uma tendência à acomodação, em manter-se na zona de conforto, que é um caminho delicioso, mas que pode impedir, por exemplo, que trabalhemos com práticas mais atrativas para o nosso aluno.

A estratégia de ensino-aprendizagem contribui efetivamente para a apreensão dos saberes, por essa razão cabe ao professor oferecer ao aluno oportunidade para estruturar o conhecimento'. Essa estruturação ocorre por meio da transformação do conhecimento em um saber fazer.

Um elemento que favorece a estratégia é a criatividade, que conforme comentado, não é privilégio de poucos, mas pode ser desenvolvida à medida que nos propomos a utilizá-la. Somos nós que lucramos quando procuramos meios de facilitar o aprendizado para nosso aluno, não só pela gratificação em vê-los aprendendo, mas porque nos tornamos mais competentes, melhoramos a autoestima, projetamos uma imagem positiva; em síntese, há uma substancial melhora em termos da percepção que temos a nosso respeito, de nossos alunos e dos indivíduos que nos cercam.

Dentre as técnicas, podemos citar: tempestade cerebral, grupos de verbalização, painéis, simpósios, seminários, debates, estudos de casos, dramatizações, oficinas, dinâmicas, excertos de textos para discussão etc. Recursos como filmes, músicas, histórias em quadrinhos também fazem parte dessas técnicas e devem ser usados com coerência. Lembramos que a técnica apoia a estratégia e isso significa que não é simplesmente trazer o filme, a música, fazer os simpósios, uma 
dramatização etc. - esses são simplesmente apoios da proposta maior que é o aprendizado e que não deve ser perdido de vista, portanto, o professor precisa aprender a ser gestor.

Gestar a sala de aula é uma tarefa complexa, o profissional deve possuir algumas características de liderança educacional, dentre elas podemos citar o envolvimento. Envolver-se é a capacidade de reconhecer as questões que não estão claras, não são óbvias e conseguir intervir para que elas sejam solucionadas. Há muitos problemas em sala de aula que não são trazidos à superfície. Por experiência, observamos que quando os alunos reclamam a respeito de determinado item, nem sempre expressam a causa. As raízes, muitas vezes, ficam camufladas, sendo que os próprios alunos podem não ter consciência a respeito. O líder que desenvolve essa característica busca aprofundar-se e evitar que a situação se agrave.

$\mathrm{O}$ envolvimento também se relaciona à mediação, ou seja, fazer com que alunos tenham bons relacionamentos interpessoais. O grupo precisa estar unido para conseguir finalizar o curso. Em outras palavras, o aluno que se sente isolado acaba desistindo da jornada.

O bom-senso também é fator primordial, pois a postura do professor é avaliada o tempo todo; assim pequenos detalhes como cuidar do vocabulário, evitar generalizações, reducionismos ou crenças ultrapassadas favorecerem a imagem profissional. A imparcialidade é sempre favorável, pois é complicado quando o aluno nota preferências por parte do professor. Naturalmente, sabemos que é do ser humano a tendência a preferir um indivíduo a outro; por isso a cautela deve permear as relações.

Julgamentos, preconceitos também compõem esse olhar. Quando um aluno tem preconceito em relação ao colega - todos relevam, mas se o professor agir dessa maneira, ele será alvo de avaliações negativas, inclusive por parte do aluno, que primeiramente manifestou o preconceito. Envolver-se, portanto, não significa agir como o aluno, mas interagir e, naturalmente, não perder de foco sua atuação como gestor.

Outra característica é o de construtor de aprendizagem - não simples transmissor de conteúdo. Essa construção deve ser compartilhada: o professor-gestor precisa motivar o aluno por meio de estratégias diversas, por exemplo, situações-problemas que estimulem os estudantes em busca de soluções. As pessoas precisam ter desafios, que sejam possíveis de solucionar e promovam crescimento individual. O ensino é coletivo, mas a aprendizagem é individual não é possível assumir a premissa de que todos que cursam o Ensino Superior têm os mesmos níveis de entendimento. Nessa linha de pensamento, ao elaborar a avaliação, devese ter cautela para que essa não se restrinja a ideia de mensurar o quanto o aluno aprendeu, mas que aponte para o caminho do que ainda precisa ser ensinado para que ele alcance os objetivos propostos.

A sociedade hoje tem escolha: professores podem discutir assuntos antes considerados tabus ou formas de expressão subversivas como ideologias e seus aparatos, teorias darwinistas, sistemas políticos, corrupção etc. Não seremos envenenados com cicuta ou queimados na fogueira por difundir ideias, mas precisamos lembrar que estamos lidando com seres humanos, que já chegam com seu repertório moldado e por essa razão é sempre importante planejar, pesquisar, analisar para não 'transmitir vírus, danificar a memória ou o hardware' do nosso aluno.

Existem muitas características não mencionadas do professor-gestor e que podem ser estudadas como forma de aprimoramento. As observações dadas servem para ajudar a memória, que já se esqueceu de suas potencialidades, mas sabemos que o entorno, as circunstâncias, a experiência, a percepção é que determinam nossas opções e 
quais caminhos devemos trilhar na sala de aula.

\section{Considerações finais}

Sabemos da importância em estabelecer bases consistentes para formação do público infantil, apesar disso insistimos que enquanto não é possível alcançar o patamar esperado nas séries iniciais, devemos continuar nossa jornada e investir nesse público adulto, propiciando formação que esteja além do tradicional banco escolar, buscando atender as necessidades individuais que auxiliem a sociedade como um todo.

Mais uma vez reiteramos que a Educação precisa ser vista além de uma escolarização voltada apenas a aspectos cognitivos - o indivíduo precisa ter formação integral ou holística, termo difundido na atualidade, para saber o que fazer com o conhecimento adquirido.

A Andragogia deve, urgentemente, ser estudada em sua complexidade, para que possamos encontrar caminhos de aprendizagem mais favoráveis ao indivíduo adulto, considerando sua subjetividade, pois o pilar que sustenta a sociedade é a Educação, por essa razão, ela não deve estar voltada apenas a aspectos relacionados à memorização de informações e/ou que se volte para questões de ordem meramente estruturais.

Propiciar condições para formação de um indivíduo integral é considerá-lo como agente no processo de construção e reconstrução, um ser capaz de avaliar e rever seus valores, de perceber-se como parte do sistema e, principalmente agir de maneira imparcial.

\section{Referências Bibliográficas}

ARANHA, Maria Lúcia de Arruda. História da Educação e da Pedagogia: geral e Brasil. 3. ed. São Paulo, Moderna: 2008.

COMENIUS, João Amós. Didactica Magna: Tratado da arte universal de ensinar tudo a todos. Lisboa: Fundação Calouste Gulbenkian, 1966.

GADOTTI, Moacir; ROMÃO José E. (Org.) Educação de Jovens e Adultos: teoria, prática e proposta. 6. ed. São Paulo: Cortez, 2003.

GIL, Antonio Carlos. Didática do Ensino Superior. São Paulo: Atlas, 2011.

GOHN, Maria da Glória. Educação não-formal e cultura política. 4. Ed. São Paulo: Cortez, 2008. LIBÂNEO, José Carlos. Organização e gestão da escola: teoria e prática. 5.ed. Goiânia: Ed. Alternativa, 2004.

NOGUEIRA, Makeliny Oliveira Gomes. Aprendizagem do aluno adulto: implicações para a prática docente no ensino superior. Curitiba: Ibpex, 2009.

PERRENOUD, Philippe. Avaliação: da excelência à regulação das aprendizagens - entre duas lógicas. Porto Alegre: Artmed. 1999.

PIMENTA, Selma Garrido. (Org.). Saberes pedagógicos e atividade docente. São Paulo, Cortez, 2009.

PIMENTA, Selma Garrido; GHEDIN, Evandro. (Org.). Professor Reflexivo no Brasil: gênese e crítica de um conceito. $4^{\mathrm{a}}$. ed. São Paulo: Cortez, 2006. 
SCHÖN, Donald. Educando o Profissional Reflexivo: um novo design para o ensino e a aprendizagem. Porto alegre: Artmed, 2000.

ZABALA, Antoni. A Prática Educativa: como ensinar. Porto Alegre: Art, 1998. Sites:

Sites:

UNESCO. Disponível em: <http://unesdoc.unesco.org/images/0018/001886/188644 por.pdf> . Acesso em: 21 set. 2011.

UNESCO. Disponível em: <http://unesdoc.unesco.org/images/0019/001910/191054por. pdf>. Acesso em: 21 set. 2011.

VOGT, M. S. L, ALVES, E.D. Revisão teórica sobre a educação de adultos para uma aproximação com a Andragogia. Disponível em: <http://coralx.ufsm.br/revce/revce/ 2005/02/a12.htm>. Acesso em: 21 set.2011.

SCHÖN, Donald. Educando o Profissional Reflexivo: um novo design para o ensino e a aprendizagem. Porto alegre: Artmed, 2000.

ZABALA, Antoni. A Prática Educativa: como ensinar. Porto Alegre: Artmed, 1998. Sites:

\section{Sites:}

UNESCO. Disponível em: < http://unesdoc.unesco.org/images/0018/001886/188644por.pdf>. Acesso em: 21 set. 2011.

UNESCO. Disponível em: < http://unesdoc.unesco.org/images/0019/001910/191054por.pdf $>$. Acesso em: 21 set. 2011.

VOGT, M. S. L, ALVES, E.D. Revisão teórica sobre a educação de adultos para uma aproximação com a Andragogia. Disponível em: <http://coralx.ufsm.br/revce/revce/ 2005/02/a12.htm>. Acesso em: 21 set.2011. 